\title{
UPDATE ON PRIMARY BILIARY CIRRHOSIS
}

\author{
Pietro Invernizzi ${ }^{1,2}$, Carlo Selmi ${ }^{1,2,3}$, and M. Eric Gershwin ${ }^{2}$ \\ ${ }^{1}$ Division of Internal Medicine and Hepatobiliary Immunopathology Unit, IRCCS Istituto Clinico \\ Humanitas, Rozzano, Italy \\ 2 Division of Rheumatology, Allergy, and Clinical Immunology, University of California at Davis, \\ Davis, CA \\ ${ }^{3}$ Department of Translational Medicine, Università degli Studi di Milano, Milan, Italy
}

\begin{abstract}
Primary biliary cirrhosis (PBC) is an autoimmune chronic liver disease characterized by progressive bile duct destruction eventually leading to cirrhosis, liver failure, and death. The autoimmune pathogenesis is supported by a plethora of experimental and clinical data, such as the presence of autoreactive $\mathrm{T}$ cells and serum autoantibodies. The etiology remains unknown, although evidence suggests a role for both genetic susceptibility and environmental factors that remain to be determined. In fact, a number of chemicals and infectious agents have been proposed to induce the disease in predisposed individuals. The recent availability of several murine models will significantly help in understanding pathphysiology mechanisms. In this review, we critically summarize the most recent data on the etiopathogenesis of PBC, discuss the latest theories and developments, and suggest directions for future research.
\end{abstract}

\section{INTRODUCTION}

\begin{abstract}
Primary biliary cirrhosis (PBC) is a chronic cholestatic liver disease characterized by an immune-mediated destruction of small and medium-size intra-hepatic bile ducts (1). The serologic hallmark of $\mathrm{PBC}$ is the presence of high-titer serum anti-mitochondrial autoantibodies (AMA), together with an increased levels of immunoglobulin $\mathrm{M}(\operatorname{IgM})$, and several disease-specific anti-nuclear antibodies (ANA) (1). PBC can be considered a peculiar organ-specific autoimmune disease from both pathogenetic and clinical points of view $(1,2)$. Indeed, PBC mainly affects middle-age women with a female to male ratio of up to 10:1 (3, 4), with only anecdotal cases reported in childhood (5). AMA are found in about $95 \%$ of patients with a very high specificity, but no direct correlation with and disease severity $(6,7)$. On the contrary, disease-specific ANA are detected in one third of patients and are associated with a more severe and rapidly progressing disease (8-10).
\end{abstract}

At presentation, patients with PBC may have symptoms such as pruritus, fatigue, and/or jaundice, but the majority are asymptomatic and diagnosed during clinical workup for other reasons, including the common autoimmune comorbidities $(11,12)$. Currently, a definite

Corresponding author: Pietro Invernizzi MD PhD, Division of Internal Medicine and Hepatobiliary Immunopathology Unit, IRCCS Istituto Clinico Humanitas, via A. Manzoni 113, 20089 Rozzano, Milan, Italy. Tel: +39 02 8224-5128, Fax: +39 02 8224-5191, pietro.invernizzi@humanitas.it.

Disclosures: No conflicts of interest exist.

Publisher's Disclaimer: This is a PDF file of an unedited manuscript that has been accepted for publication. As a service to our customers we are providing this early version of the manuscript. The manuscript will undergo copyediting, typesetting, and review of the resulting proof before it is published in its final citable form. Please note that during the production process errors may be discovered which could affect the content, and all legal disclaimers that apply to the journal pertain. 
diagnosis of $\mathrm{PBC}$ is made on a combination of abnormal serum enzymes indicating cholestasis (i.e. elevated alkaline phosphatase for at least six months), the presence of serum AMA (titer $\geq 1: 40$ ), and characteristic histology with florid bile duct lesions (13). A probable diagnosis is made when two out of these three criteria are present but this definition is not widely accepted. Serum AMA may precede disease onset by several years but individuals found positive for these autoantibodies in the absence of other criteria will eventually develop PBC during follow up (14).

Although several experimental as well as clinical findings support autoimmune mechanisms for biliary damage in $\mathrm{PBC}(2,15)$, the underlying cause of the disease remains largely unknown. The current hypothesis on the etiopathogenesis of PBC implies that susceptibility is secondary to genetic predisposition elements that are permissive for host-environmental interactions, similar to other autoimmune diseases (16). However, the past decade has witnessed several key advances in understanding the effector mechanisms of PBC. Several lines of evidence suggest that the primary event in $\mathrm{PBC}$ is the loss of tolerance to the $\mathrm{E} 2$ subunit of pyruvate dehydrogenase (PDC-E2), the immunodominant AMA autoantigen. They also suggest that the destruction of biliary epithelium is based in part upon its unique apoptotic properties in which the mitochondrial autoantigens remain immunologically intact (17). Furthermore, several animal models with autoimmune cholangitis have now been described, each with unique features that recapitulate the human condition.

This review is timely, since we are witnessing an enormous amount of solid data on the immunomolecular mechanisms underlying the disease onset and perpetuation, which we believe will allow soon to give fundamental answers. To this regard, we will first discuss the role of genetic, epigenetic, and environmental factors in triggering the autoimmune aggression against bile ducts with focus on the recent data from a genome wide association study. We will then discuss the female predominance in autoimmunity focusing on the presence of major sex chromosome defects in women with PBC. We will then illustrate several new lines of research on the target organ and the role of innate immunity, mainly based on animal model studies. Finally, we will discuss the expanding repertoire of immune-serological diagnostic and prognostic markers while newer treatments will not be discussed (18-20).

\section{GENETICS FACTORS}

As for many autoimmune disorders, genetic factors are known to play a decisive role in conferring PBC susceptibility (21) but are not related to a single gene but to a complex multigenes trait.

\section{Familial and twin aggregation data}

The first insights in a genetic component came from early epidemiological studies showing a higher incidence of disease among first-degree relatives of patients (11). Cumulatively, family aggregation data indicate that up to $6 \%$ of PBC patients have at least one family member manifesting the disease. It is to note that a recent study from the US demonstrated that there is an increased incidence of AMA without any sign of disease in first-degree relatives and offspring of patients with $\mathrm{PBC}$, thus indirectly suggesting the existence of a strong genetic predisposition (22).

More recent data further strengthen the relevance of the multifactorial genetic basis in PBC, including a high concordance rate among monozygotic (identical) twins (23), and the observation that lymphocytes from women with $\mathrm{PBC}$ preferentially loose one $\mathrm{X}$ chromosome $(24,25)$. It is of note that while among autoimmune disorders concordance rate in monozygotic twins have been shown to be on average below 50\%, the PBC concordance rate is as high as $63 \%$ in 8 monozygotic sets but null among dizygotic twins (23). However, since in some 
concordant sets, PBC phenotype varied significantly within one pair, it can be hypothesized that other factors, including epigenetics $(4,26-28)$, exposure to environmental factors, or mere serendipity, may play a role complementary to genetics.

\section{Case-control association studies}

Up until most recently, to identify susceptibility gene(s) that predispose for the development of $\mathrm{PBC}$ remained a challenge. The majority of studies on the etiopathogenesis of $\mathrm{PBC}$ have focused upon candidate gene based association studies and were limited by sample size and poor selecting and control matching criteria. They mainly focused on immune-related genes with role in maintaining tolerance and belonging to both the HLA loci and non-HLA immune modulators genes $(29,30)$. Unfortunately, the large part of these studies reported weak and often contrasting associations $(29,30)$, with the only exception of the consistent associations found within the HLA region (31-33). Indeed, in contrast to earlier work, we and others recently demonstrated that PBC is not only associated with the HLA DRB $1 * 08$ allele but also with two protective alleles, HLA DRB $1 * 11$ and DRB $1 * 13(31,32,34)$. Furthermore, a most recent Canadian-US study reported the first genome-wide association study and confirmed the key role in PBC susceptibility of common genetic variants in the HLA class II loci (33). Of great interest, this study also demonstrated that genes encoding for interleukin 12 and its receptor are associated with susceptibility to $\mathrm{PBC}$ (33). These findings needs to be confirmed in independent cohorts with a larger number of subjects and variants genotyped, but the functional role of these molecules should be carefully evaluated in the near future.

\section{ENVIRONMENTAL FACTORS}

Despite the key role played by genetics in PBC susceptibility, genes are not sufficient to trigger the disease and we submit that exposure to certain environmental factor(s), even not harmful per se, may cause the breakdown of immune tolerance and $\mathrm{PBC}$ onset. The role of two main environmental factors have been evaluate in PBC, i.e. xenobiotics (i.e. chemical compounds), and infectious agents (viruses and bacteria) $(35,36)$.

\section{Xenobiotics}

Experimental and epidemiology evidence, as well as animal models, support the strong role of environmental factors including xenobiotics in the development of PBC, as illustrated by the discordant monozygotic twin sets previously discussed.

Xenobiotics are compounds foreign to the human system. The possible mechanisms through which xenobiotics may trigger an auto-immune response to self proteins are based on the hypothesis that they may modify their molecular structures or complex to self or non-self proteins to generate neoantigens. Therefore, the altered protein may induce an auto-immune response, as is the case for molecular mimicry. Our group recently suggested a possible pathogenic role of an organic compound in PBC. In particular, a specific halogenated organic compound was able to elicit AMA production by sera from patients with $\mathrm{PBC}$ once attached to the major mitochondrial epitope backbone (37). This because antibodies against such modified mitochondrial epitope had a higher affinity than antibodies directed against to the native epitope (37). With a subsequent study based on a multiplex approach, 2-nonynoic acid was found to be recognized by patient serum antibodies which did not cross-react with the PDC-E2 native form. This is very important since 2-nonynoic acid does not occur naturally and is found in several cosmetic products, including nail polish (11).

\section{Infectious agents}

Early epidemiological studies provided the first insight on the role of infectious agents as potential triggers of PBC (38). Indeed, several authors reported that patients with $\mathrm{PBC}$ have 
urinary tract infections more frequently than controls, E. coli being the main etiological agent. More recently, an epidemiological study on 1032 patients with PBC and 1041 controls (11) not only confirmed the association of an enhanced risk of PBC and recurrent urinary tract infections but also increased risk of vaginal infections along with lifestyle factors such as smoking. Interestingly, we also showed that subjects who frequently use nail polish was associated with an enhanced risk of develop PBC.

Molecular mimicry is a widely accepted mechanism by which infectious agents may trigger autoimmune aggression in autoimmune diseases, including PBC. Infectious agents may indeed trigger a promiscuous antibody- and cell-mediated immune response, because they share a good degree of amino acid similarity. The highly conserved sequence of mitochondrial enzymes across all species also strengthens this view. Besides E. coli, a number of other bacteria have been shown as cross-reactive agents in PBC, including Proteus mirabilis, Klebsiella pneumoniae, Staphylococcus aureus, Neisseria meningitidis, Salmonella minnesota, Mycobacterium gordonae, and Trypanosoma brucei (38). We recently provided serological and molecular evidence suggesting that Novosphingobium aromaticivorans, a ubiquitous xenobiotic-metabolizing Gram-negative bacterium, is possibly an ideal candidate for the induction of PBC (39) for two reasons: first, it contains two proteins with the highest degree of homology with the major epitope of PDC-E2, and secondly $N$. aromaticivorans can metabolize organic compounds and estrogens. We also reported that the bacterium can elicit a specific antibody reactivity (up to 1000-fold higher than against $E$. coli) in PBC but not in control sera (39). Furthermore, N. aromaticivorans induced serum autoantibodies and PBCspecific liver features in a murine model (40).

It has been previously reported that a novel human beta-retrovirus was found in peri-hepatic lymph nodes and other biological samples from patients with PBC. However, our group could not replicate these findings and neither confirm such hypothesis in an independent study based on a larger series of cases and controls (41). In addition, human beta-retrovirus has been recently found in the liver of patients affected by other liver diseases, including autoimmune hepatitis and viral hepatitis as well as healthy controls (42), thus excluding a specific role of this virus in $\mathrm{PBC}$ if not as an epiphenomenon. These data cumulatively discourage the use of antiviral therapies proposed to treat $\mathrm{PBC}$ (43).

\section{FEMALE PREPONDERANCE}

Similar to other autoimmune diseases, $\mathrm{PBC}$ is characterized by a striking female predominance, with a female to male ratio estimated as 10 to $1(3,4,26)$. So far, the reason for this observation remains unknown, but a role of fetal microchimerism, sex hormones, or X chromosome defects has been proposed.

\section{Fetal microchimerism}

One hypothesis on the PBC female predominance was the persistence of fetal cells and genomic materials in women years after pregnancy, a phenomenon coined fetal microchimerism. Fetal cells are semi-allogenic to the maternal immune system and thus might mediate a graft-versus host disease-like reaction in women. Fetal cells were reported in blood and tissues from women with autoimmune diseases, such as scleroderma. Conversely, most of the studies failed to find significant difference in frequency of fetal microchimerism in women with PBC compared to controls $(44,45)$. Based on these data, we are convinced that fetal microchimerism does not play a major role in $\mathrm{PBC}$, although it is possible that it is involved in the pathogenesis of other autoimmune diseases. 


\section{Sex hormones}

Although sex hormones were widely investigated in the last five decades and have a number of immunomodulatory functions (46), we rule them out as major responsible for the female predominance in PBC. However, estrogens could have direct effects on cholangiocytes, the specific target organ in PBC, since these cells express estrogen receptors (47). In particular, it has been shown that cholangiocytes from patients with advanced histological stages do not express estrogen receptors, thus suggesting a role of estrogen deficiency in the development of ductopenia in PBC. However, the possible influence of estrogens on PBC onset and perpetuation needs to be confirmed and further investigated (47).

\section{Sex chromosomes}

Few studies have investigated sex chromosomes in autoimmunity. We have recently proposed a novel hypothesis on the female predominance of autoimmunity based on major defects of sex chromosomes $(3,4)$. This theory is based on three observations. First, diseases due to $\mathrm{X}$ monosomy or its major abnormalities, such as Turner's syndrome (48) or premature ovarian failure (49), are frequently associated with autoimmune features and in some cases chronic cholestasis. Second, a number of genes that are key factors in the maintenance of immune tolerance, such as FoxP3, map on the X chromosome (21). Third, diseases due to defect in single $\mathrm{X}$-linked genes, such as $\mathrm{X}$-linked immunodeficiency, are characterized by a plethora of autoimmune features (50). The biology of $\mathrm{X}$ chromosome is quite complex compared to other chromosomes as women are functional mosaics for X-linked genes, with most genes on one $\mathrm{X}$ chromosome being silenced as a result of X-chromosome inactivation (XCI) to achieve equivalent levels of $\mathrm{X}$-linked gene products between sexes. However, more recent data have shown that the picture is even more complex by demonstrating that at least $15 \%$ of $X$-linked genes escape XCI in healthy women and are thus expressed from both X chromosomes (51). A role for $\mathrm{X}$ chromosome was first proposed based on experimental evidence that women with PBC have a significantly higher frequency of peripheral blood cells with a single $\mathrm{X}$ chromosome (i.e. X monosomy) compared to healthy age-matched women (24). Importantly, this difference was confirmed also in other autoimmune diseases, such as systemic sclerosis and autoimmune thyroid disease (52), but not in women with systemic lupus erythematosus $(53,54)$. We also demonstrated that in PBC (and possibly in other autoimmune disorders) X chromosome loss is preferential and involves more frequently a single parentally inherited $\mathrm{X}$ chromosome (25). Other than chromosome loss, it has been also reported that women with autoimmune diseases have a non-random XCI pattern in their circulating blood cells $(55,56)$, thus suggesting a gene dosage effect of $\mathrm{X}$-linked genes but such preferential inactivation was not found in PBC (25) and in other autoimmune disorders (57).

\section{ANIMAL MODELS}

As in other complex diseases, the development of an animal model is of great importance in dissecting the mechanism underlying the initiation and progression of PBC. In the last few years, several murine models of PBC $(2,58)$ have been proposed and their major features are illustrated in Table 1. Mouse strains have been reported to be spontaneous PBC model animals and two among these animal models, IL-2R $\alpha$ knockout and dnTGFßRII selective knock-out mice, strongly indicate the possible role of Tregs deficiency in PBC onset. In particular, the mouse deficient for IL2 receptor $\alpha$ (IL-2R $\alpha$ ), which is highly expressed on T regs, developed AMA positivity against PDC-E2 in all animals, $80 \%$ ANA positivity, and lymphocyte infiltration around the portal tracts associated with cholangiocyte injury (59). The dominant negative form of transforming grown factor $\beta$ (TGF $\beta$ ) receptor II, (dnTGF $\beta$ RII) manifests PBC-like liver disease, such as 100\% AMA positivity against PDC-E2 (60). TGF $\beta$ receptor II is known to be essential for signal transduction of TGF $\beta$ to regulate lymphocytes activation (61). A third animal model is a variant of the non-obese diabetic (NOD) mouse model 
(NOD.c3c4). It has been described that NOD.c3c4 mouse develops autoimmune cholestasis and PBC-specific serology, showing AMA positivity in up to $60 \%$ of sera and ANA positivity in about $90 \%$. Histologically, there is lymphocyte infiltration around portal tracts with epithelioid granuloma formations and chronic nonsuppurative destructive cholangitis; However, the morphological features of bile duct damage differ from those in human PBC, particularly because of the occurrence of cystic changes (62).

Other useful models for PBC have been subsequently developed by immunization with xenobiotically modified molecular variants of the PDC-E2 epitope $(2,58)$. Firstly, we showed loss of tolerance in rabbits immunized with 6-bromohexonate, a xenobiotically modified hapten mimicking lipoic acid. The immunized rabbits produced very high titer AMA directed at PDC-E2 other than antibodies against the xenobiotic, but did not induce PBC-specific hepatic lesions at least in the short follow-up (63). Finally, induction of specific PBC features was obtained in guinea pigs (64) and in a NOD background (65) exposed to xenobiotic immunization. All these models share some similarities with the human condition (66), yet manifest specific peculiarities.

\section{CELLULAR IMMUNITY}

\section{Autoreactive T cells}

The involvement of cellular immune mechanisms in the biliary damage is clearly suggested by the presence of high number of helper (CD4+) TCR $\alpha \beta+$ and CD8+ T cells in the portal tracts from patients with PBC (67-72). Autoreactive PDC-E2-specific CD4 T cells have been reported both in peripheral blood and liver tissue of patients with PBC but not in healthy and disease controls. In support of their role in the liver damage, a 150-fold increase in number of CD4 T cells specifically targeting PDC-E2 was found in the peri-hepatic lymph nodes and liver compared with blood of patients with PBC. Our group also characterized the antigen specificity of these cells and demonstrated that in HLA DR4*0101 positive patients autoreactive CD4 T cells recognized a single epitope of 163-176 aa sequence which encompass the lipoic acid binding residue of the inner lipoyl domain of PDC-E2 which is shared by serum AMA. Finally, we showed that these cells are of pro-inflammatory nature only in PBC patients but not in controls, based on the production of pro-inflammatory cytokines such as IFN- $\gamma(69)$, as later confirmed in peripheral blood (73).

Based on a plethora of data, autoreactive CD4+ and CD8+ T cells are believed to be involved in the pathogenesis of PBC and liver infiltration of these cells is one of the major features of the disease (2), including in AMA-negative cases (74). However, findings point to a predominant role for the CD8+ T subpopulation in $\operatorname{PBC}(75,76)$. It is of note that the HLA class I restricted epitope for CD8+ T cells, i.e. 159-167 aa sequence, maps closely to the epitopes recognized by serum AMA as well as by CD4 T cells, that is the autoepitope for both CD4 and CD8 T cells overlaps with the B cell (AMA) epitope. As for autoreactive CD4+ T cells, we showed a 10-fold higher frequency of PDC-E2159-167 specific CD8 T cells within the liver compared to blood of $\mathrm{PBC}$ patients. Functionally, it has been shown that autoreactive CD8 T cells in this disease have the ability to produce IFN- $\gamma$ rather than IL-4/IL-10 cytokines (77), but also IL-17 has been recently suggested to be crucial in PBC (76).

\section{Regulatory T cells (Tregs)}

Despite extensive data on both autoantibody and autoreactive $\mathrm{T}$ cells, the mechanisms that lead to loss of tolerance in $\mathrm{PBC}$ have proven elusive. From a generic perspective there is considerable discussion that suggests that defects in the regulatory $\mathrm{T}$ cell (Treg) compartment are responsible for antigen specific loss of tolerance (78), possibly based on genetic mechanisms (79). However, this has been difficult to prove in vivo and, despite widely 
observed, quantitative and/or functional impairments of Tregs in humans and animal models, it has been difficult to link these observations to bile duct specific autoimmunity. $\mathrm{PBC}$ is overwhelmingly a syndrome of adults, although interestingly there is a PBC-like disease reported in a child with IL-2 receptor $\alpha$ (CD25) deficiency (80). This observation is particularly intriguing because of data from murine models of autoimmune cholangitis $(59,60,81)$ in which CD8 T cells play a critical role in the loss of Treg function in mice (75). We should also note that quantitative and functional analysis of intrahepatic and circulating Tregs in humans with PBC suggest a loss of T regulatory function (82-84) but these studies have focused entirely on CD4+CD25 Treg cells. Based on the murine data, in the future it would be important to specifically address and analyze the CD8 Treg populations in patients with PBC.

\section{Innate immunity cells}

While adaptive immunity recognizes antigens with high specificity, the innate immunity system, including monocytes, dendrocytes, and natural killer (NK) cells, recognizes distinct evolutionarily conserved structures generally shared by pathogens and known as pathogenassociated molecular patterns (PAMPs), and thus allow a rapid recognition and elimination of infectious agents. PAMPs are known to bind to toll-like receptors (TLRs) which then modulate the function of both adaptive cellular and humoral immunity (85). Of note, the liver is considered both structurally and functionally as a major organ of innate immunity, since it contains the largest resident population of cells of the innate immune system. Growing data indicate that the innate immune system contributes to the triggering and perpetuation of liver damage. In particular, $\mathrm{PBC}$ exhibits specific immunological features in support of this view, such as elevated levels of serum IgM in response to bacterial antigens, the presence of epitheliod granulomas, increased levels of cytokines response and enhanced-responsiveness to PAMPs by NK cells and monocytes, as explained in details below. Almost all patients with PBC have elevated IgM levels, independently of their AMA or ANA status (1). A polyclonal hyper-IgM was found to be secondary to a chronic polyclonal innate immune response of memory B cells to bacterial unmethylated $\mathrm{CpG}$ motifs (86). Moreover, our group also demonstrated that B cells exposed to CpG motifs express increased amount of CD86 and TRL9 as well as increased production of autoantibodies. These data support a link between bacteria and $\mathrm{PBC}$ and strongly suggests a key role for B cells dysregulation in PBC (87).

PBC monocytes have a pro-inflammatory activity which is enhanced in PBC. More specifically, monocytes activated by PAMPs through TLRs release pro-inflammatory cytokines, such as IL-1, IL-6, IL-12, IL-18, and TNF- $\alpha$ which then amplifies the adaptive T cell mediated immune response against infectious agents. We demonstrated that circulating monocytes from PBC patients challenged with various PAMPs specific for TLR2, TLR3, TLR4, TLR5, and TLR9 lead to high levels of all pro-inflammatory cytokines when compared with cells from controls (88). The mechanisms for such increased sensitivity may well be secondary to the higher frequency of recurrent urinary tract infections reported in PBC. It is also possible that both monocytes and B cells constantly exposed to bacterially derived products (PAMPs) gathered from the portal circulation participate in modulating the adaptive cellular immune response.

In more recent years, NK T cells are attracting growing attention in autoimmunity (89), being innate effector cells regulated by self and non-self glycolipid antigens presented by the antigenpresenting molecule CD1d (90). Such activation leads to a rapid production of cytokines and chemokines by NK T cells, with consequent modulation of both the adaptive and innate immune responses. In an early study, we reported a higher frequency of CD1d-restricted NKT cells in PBC patients compared to controls and that these were more frequent in the liver compared to peripheral blood of patients (72). Subsequently, we confirmed an increased number of CD1d-restrcited NKT cells also in the liver of dnTGFßRII mice, one of the 
comprehensive PBC murine models. Finally, we also reported that CD1d-deficient dnTGFßRII mice had a reduced hepatic lymphoid cell infiltrates and milder cholangitis compared to controls (89).

Although innate immunity hyper-responsiveness is likely not sufficient to cause the loss of immune tolerance, we hypothesize that these alterations might play a role in triggering the autoimmune pathology. In this scenario, it is intriguing that in a murine model of PBC $N$. aromaticivorans was able to induce the production of serum AMA and chronic cellularmediated autoimmunity against small bile ducts in an NK T cell dependent fashion (40).

\section{AUTOANTIBODIES}

\section{Anti-mitochondrial antibody (AMA)}

Serum AMA are widely accepted as the diagnostic hallmark of PBC and found in nearly $100 \%$ of affected individuals when tested using techniques based on recombinant mitochondrial antigens (via immunoblotting or ELISA) (7,91). The extremely high sensitivity and specificity of AMA make them one of the most specific diagnostic tests of human diseases $(6,91)$. AMA specifically recognizes lipoilated domains within components of the 2-oxoacid dehydrogenase (OADC) family of enzymes within the mitochondrial respiratory chain, particularly the dihydrolipoamide acetyltransferase (E2 component) of the pyruvate dehydrogenase complex (PDC). Less frequent autoantigens are the $\mathrm{E} 2$ components of 2-oxo glutarate dehydrogenase (OADC-E2) and branched-chain 2-oxo acid dehydrogenase (BCOADC-E2) complexes, the E3 binding protein (E3BP) and the E1 $\alpha$ subunit of the pyruvate dehydrogenase complex (PDCE1 $\alpha$ ) $(7,92,93$ ) (Table 2). Indirect immunofluorescence (IIF) using rodent liver, kidney and stomach sections as substrate, is still the most widely used screening assay for AMA in the routine setting (13), although immunoblotting and ELISA have an higher sensitivity, and the use of cloned mitochondrial antigens and bead assay testing system (94) allow to identify AMA in the sera of patients previously defined as AMA negative. Although extremely useful as diagnostic marker, AMA are not clinically helpful during follow-up as several studies demonstrate that they do not correlate with stage (95). It is also to note that AMA are often detectable for several years before the onset of overt clinical disease (14).

\section{Anti-nuclear antibody (ANA)}

Serum ANA are detected in approximately one third of sera from patients with PBC, and reportedly more frequently in AMA-negative cases $(8,96)$. Over the last three decades, several nuclear structures have been identified as specific targets of ANA in PBC (10), with the two most frequent patterns being "multiple nuclear dots" (ND) in which the antigens recognized are the Sp100 and promyelocytic leukemia proteins (PML), and "perinuclear" based on gp210 and nucleoporin p62 antigens localized within the nuclear pore complex (NPC). Both the perinuclear and nuclear dot ANA patterns are very specific for PBC (97) (Table 2), while anti centromere autoantibodies (ACA) are not specific and found in only $10 \%$ of PBC patients (98), similar to other autoantibodies (99). Of interest, the ANA specificities have been found more frequently in patients with severe disease in cross-sectional studies $(8,96-98,100,101)$ and, even more interestingly, the presence of anti-NPC is associated with worst prognosis ( 9 , 102-104) in longitudinal observations. These data have obvious relevant implications for the clinical management of PBC since anti-NPC and ACA testing are important for identifying asymptomatic patients with an unfavorable disease outcome and warranting early therapy (7). Unfortunately, the pathogenic role of these antibodies has been poorly investigated and remains unknown. 


\section{BILIARY EPITHELIAL CELLS (BEC)}

PBC is characterized by a highly selective destruction of the small and medium size intrahepatic bile ducts, lined by BEC (i.e. cholangiocytes). It has been demonstrated that BEC express cell surface adhesion molecules which permit adhesion and recognition of lymphocytes. In addition, a number of studies have demonstrated that BEC of both healthy and diseased liver have the capacity to increase the expression of adhesion molecules, such as ICAM-1 and others, TNF- $\alpha$, MHC class I and II, IFN- $\gamma$ and IL-1 upon stimulation with pro-inflammatory cytokines. Adhesion molecules expressed on BEC, along with the enhanced levels of pro-inflammatory cytokines, allow BEC to modulate the intensity and localization of inflammatory reactions. Moreover BEC have the capacity to act as antigen presenting cells, expressing HLA class II $(105,106)$, and accessory molecules responsible for the co-stimulatory signal to $\mathrm{T}$ cells, CD80,86 (B7-1, B7-2). The interactions between BEC and T cells might be responsible for bile duct loss, a key characteristic of progression of disease.

Antigenicity of BEC self-molecules, or highly homologous epitopes, could also be related to their role in mucosal immunity. As other epithelial cells, BEC actively transfer IgA-AMA specific for PDC-E2. Interestingly, these specific IgA-type AMA can be detected in all body fluids of patients with PBC, including saliva, bile, and urine $(107,108)$. Matsumura and colleagues provided evidence for direct toxic effects of AMA-IgA by exposing canine kidney cells transfected with the human polymeric Ig receptor to highly purified AMA-IgA (109). Overall, the immunogenic characteristics of BEC in PBC are summarized in Table 3.

Apoptosis of BECs in PBC may prove crucial for immune tolerance loss $(17,110)$, as in other conditions (110). Odin and colleagues reported that the glutathiolation of the lysine-lipoic acid moiety of PDC-E2 was reduced by serum AMA (111). Most recently our group demonstrated that BEC expose intact immunoreactive PDC-E2 within apoptotic blebs from cells undergoing apoptosis (17), thus suggesting that the unique characteristics of BECs during apoptosis may explain the tissue specificity of the autoimmune injury in $\mathrm{PBC}$ (112) although experimental data suggest that BEC may in fact be innocent victims of the autoimmune injury (68).

\section{HYPOTHESIS ON PBC ETIOPATHOGENESIS}

Following this discussion of available data, it is possible to propose a unifying view. Three major events are crucial to the proposed mechanism leading to the breakdown of tolerance and the resulting PBC onset and perpetuation, i.e. BEC apoptosis, female predominance, and genetic susceptibility. A microorganism (possibly the ubiquitous $N$. aromaticivorans) with highly similar proteins to human PDC-E2 enters the human system through the digestive mucosa and its mimicking proteins are modified within the liver by xenobiotics to form immunoreactive antigens. These modifications could be then sufficient to trigger the innate immune system to initiate a cascade of local inflammatory events resulting in local dendritic cell activation and antigen processing. Mucosal antigen-presenting cells in turn could activate autoreactive T and B cells (16) that are directed to the liver through the portal system. T cells, therefore, could participate directly not only to the autoimmune injury, but also to its amplification and perpetuation (68). B cells, on the other hand, could secrete AMA, particularly of the IgA type. AMA-IgA could be then transported to the vascular side of biliary epithelial cells where they could recognize PDC-E2-like molecules located on the luminal surface cell membrane. AMA-IgA/PDC-E2-like molecules engagement could initiate apoptotic signaling cascade. Ultimately, the immune complexes of post-apoptotic PDC-E2 and IgG-AMA and the direct cytopathic effects of autoreactive T cells (and possibly AMA) lead to the selective BEC targeting and autoimmune cholangitis development. 


\section{CONCLUSIONS AND FUTURE PERSPECTIVES}

There have been substantial advances in the understanding of PBC pathogenesis since the molecular identification of PDC-E2 in 1987 as the major autoantigen of AMA (92). A number of questions on the etiology and pathogenesis of $\mathrm{PBC}$ still need to find an answer but we believe that soon we will be able to solve the puzzle. We are also convinced that to achieve this goal, our efforts should be mainly dedicated to overcoming some logistic difficulties. Firstly, we encourage the collection of very large series of patients and controls, possibly by mean of multicentric studies, and the use of genome-wide analysis on thousands of genetic and epigenetic variants. This will allow defining the individual bases of PBC. Secondly, based on the most recent evidence, the role of innate immunity in the onset and perpetuation of $\mathrm{PBC}$ should be further studied. Third, it is time to prove the AMA pathogenic role in PBC. Fourth, it will be important to develop additional animal models to better dissect the molecular mechanisms underlying the disease. Finally, we are convinced that the growing evidence on the key role of apoptosis in PBC will provide some intriguing data in the near future. Ultimately, we believe that while new frontiers are being proposed $(113,114)$ we will be able to understand the etiopathogenesis of $\mathrm{PBC}$ only through a multidisciplinary approach uniting clinicians, basic immunologists, geneticists, chemists, and microbiologists, possibly through the proposed role of an autoimmunologist (115).

\section{Acknowledgments}

Grant support: Supported by NIH grant DK39588.

\section{Abbreviations}

$\begin{array}{ll}\text { PBC } & \text { primary biliary cirrhosis } \\ \text { AMA } & \text { anti-mitochondrial antibodies } \\ \text { IgM } & \text { immunoglobulin M } \\ \text { ANA } & \text { anti-nuclear antibody } \\ \text { PDC-E2 } & \text { E2 subunit of pyruvate dehydrogenase } \\ \text { HLA } & \text { human leukocyte antigen } \\ \text { XCI } & \text { X-chromosome inactivation } \\ \text { dnTGF } \beta \text { RII } & \text { dominant negative form of transforming grown factor } \beta \text { receptor II } \\ \text { NOD } & \text { non-obese diabetic } \\ \text { Treg } & \text { regulatory T cell } \\ \text { NK } & \text { natural killer } \\ \text { PAMPs } & \text { pathogen-associated molecular patterns } \\ \text { TLRs } & \text { toll-like receptors } \\ \text { OADC } & \text { 2-oxoacid dehydrogenase } \\ \text { OADC-E2 } & \text { E2 components of 2-oxo glutarate dehydrogenase } \\ \text { BCOADC-E2 } & \text { E2 components of branched-chain 2-oxo acid dehydrogenase } \\ \text { E3BP } & \text { E3 binding protein } \\ \text { PDC-E1 } \alpha & \text { E1 } \alpha \text { subunit of the pyruvate dehydrogenase complex } \\ \text { IIF } & \text { Indirect immunofluorescence }\end{array}$




$\begin{array}{ll}\text { ND } & \text { nuclear dots } \\ \text { PML } & \text { promyelocytic leukemia proteins } \\ \text { NPC } & \text { nuclear pore complex } \\ \text { ACA } & \text { anti-centromere antibodies } \\ \text { BEC } & \text { biliary epithelial cells }\end{array}$

\section{References}

1. Kaplan MM, Gershwin ME. Primary biliary cirrhosis. N Engl J Med 2005;353:1261-1273. [PubMed: 16177252]

2. Gershwin ME, Mackay IR. The causes of primary biliary cirrhosis: Convenient and inconvenient truths. Hepatology (Baltimore, Md 2008;47:737-745.

3. Invernizzi P. Future directions in genetic for autoimmune diseases. Journal of autoimmunity 2009;33:1-2. [PubMed: 19410428]

4. Invernizzi P, Pasini S, Selmi C, et al. Female predominance and X chromosome defects in autoimmune diseases. Journal of autoimmunity 2009;33:12-16. [PubMed: 19356902]

5. Invernizzi P. Geoepidemiology of autoimmune liver diseases. Journal of autoimmunity. 2009

6. Oertelt S, Rieger R, Selmi C, et al. A sensitive bead assay for antimitochondrial antibodies: Chipping away at AMA-negative primary biliary cirrhosis. Hepatology (Baltimore, Md 2007;45:659-665.

7. Invernizzi P, Lleo A, Podda M. Interpreting serological tests in diagnosing autoimmune liver diseases. Seminars in liver disease 2007;27:161-172. [PubMed: 17520516]

8. Invernizzi P, Podda M, Battezzati PM, et al. Autoantibodies against nuclear pore complexes are associated with more active and severe liver disease in primary biliary cirrhosis. Journal of hepatology 2001;34:366-372. [PubMed: 11322196]

9. Wesierska-Gadek J, Penner E, Battezzati PM, et al. Correlation of initial autoantibody profile and clinical outcome in primary biliary cirrhosis. Hepatology (Baltimore, Md 2006;43:1135-1144.

10. Invernizzi P, Selmi C, Ranftler C, et al. Antinuclear antibodies in primary biliary cirrhosis. Seminars in liver disease 2005;25:298-310. [PubMed: 16143945]

11. Gershwin ME, Selmi C, Worman HJ, et al. Risk factors and comorbidities in primary biliary cirrhosis: a controlled interview-based study of 1032 patients. Hepatology (Baltimore, Md 2005;42:11941202.

12. Hudson M, Rojas-Villarraga A, Coral-Alvarado $P$, et al. Polyautoimmunity and familial autoimmunity in systemic sclerosis. Journal of autoimmunity 2008;31:156-159. [PubMed: 18644698]

13. EASL Clinical Practice Guidelines: management of cholestatic liver diseases. Journal of hepatology 2009;51:237-267. [PubMed: 19501929]

14. Metcalf JV, Mitchison HC, Palmer JM, et al. Natural history of early primary biliary cirrhosis. Lancet 1996;348:1399-1402. [PubMed: 8937278]

15. Lleo A, Invernizzi P, Mackay IR, et al. Etiopathogenesis of primary biliary cirrhosis. World J Gastroenterol 2008;14:3328-3337. [PubMed: 18528930]

16. Shimoda S, Harada K, Niiro H, et al. CX3CL1 (fractalkine): A signpost for biliary inflammation in primary biliary cirrhosis. Hepatology (Baltimore, Md. 2009

17. Lleo A, Selmi C, Invernizzi P, et al. Apotopes and the biliary specificity of primary biliary cirrhosis. Hepatology (Baltimore, Md 2009;49:871-879.

18. Marmont AM. Will hematopoietic stem cell transplantation cure human autoimmune diseases? Journal of autoimmunity 2008;30:145-150. [PubMed: 18222646]

19. Burt RK, Testori A, Craig R, et al. Hematopoietic stem cell transplantation for autoimmune diseases: what have we learned? Journal of autoimmunity 2008;30:116-120. [PubMed: 18242956]

20. Yaniv I, Ash S, Farkas DL, et al. Consideration of strategies for hematopoietic cell transplantation. Journal of autoimmunity. 2009 
21. Invernizzi P, Gershwin ME. The genetics of human autoimmune disease. Journal of autoimmunity. 2009

22. Lazaridis KN, Talwalkar JA. Clinical epidemiology of primary biliary cirrhosis: incidence, prevalence, and impact of therapy. J Clin Gastroenterol 2007;41:494-500. [PubMed: 17450033]

23. Selmi C, Mayo MJ, Bach N, et al. Primary biliary cirrhosis in monozygotic and dizygotic twins: genetics, epigenetics, and environment. Gastroenterology 2004;127:485-492. [PubMed: 15300581]

24. Invernizzi P, Miozzo M, Battezzati PM, et al. Frequency of monosomy X in women with primary biliary cirrhosis. Lancet 2004;363:533-535. [PubMed: 14975617]

25. Miozzo M, Selmi C, Gentilin B, et al. Preferential X chromosome loss but random inactivation characterize primary biliary cirrhosis. Hepatology (Baltimore, Md 2007;46:456-462.

26. Invernizzi P. Role of X chromosome defects in primary biliary cirrhosis. Hepatol Res 2007;37 (Suppl 3):S384-388. [PubMed: 17931191]

27. Invernizzi P, Pasini S, Selmi C, et al. Skewing of X chromosome inactivation in autoimmunity. Autoimmunity 2008;41:272-277. [PubMed: 18432407]

28. Sanchez-Pernaute O, Ospelt C, Neidhart M, et al. Epigenetic clues to rheumatoid arthritis. Journal of autoimmunity 2008;30:12-20. [PubMed: 18155418]

29. Invernizzi P, Selmi C, Mackay IR, et al. From bases to basis: linking genetics to causation in primary biliary cirrhosis. Clin Gastroenterol Hepatol 2005;3:401-410. [PubMed: 15880308]

30. Invernizzi P, Gershwin ME. The genetic basis of primary biliary cirrhosis: premises, not promises. Gastroenterology 2008;135:1044-1047. [PubMed: 18773895]

31. Invernizzi P, Selmi C, Poli F, et al. Human leukocyte antigen polymorphisms in Italian primary biliary cirrhosis: a multicenter study of 664 patients and 1992 healthy controls. Hepatology (Baltimore, Md 2008;48:1906-1912.

32. Donaldson PT, Baragiotta A, Heneghan MA, et al. HLA class II alleles, genotypes, haplotypes, and amino acids in primary biliary cirrhosis: a large-scale study. Hepatology (Baltimore, Md 2006;44:667-674.

33. Hirschfield GM, Liu X, Xu C, et al. Primary Biliary Cirrhosis Associated with HLA, IL12A, and IL12RB2 Variants. N Engl J Med. 2009

34. Invernizzi P, Battezzati PM, Crosignani A, et al. Peculiar HLA polymorphisms in Italian patients with primary biliary cirrhosis. Journal of hepatology 2003;38:401-406. [PubMed: 12663229]

35. Van de Water J, Ishibashi H, Coppel RL, et al. Molecular mimicry and primary biliary cirrhosis: premises not promises. Hepatology (Baltimore, Md 2001;33:771-775.

36. Christen U, Hintermann E, Holdener M, et al. Viral triggers for autoimmunity: Is the 'glass of molecular mimicry' half full or half empty? Journal of autoimmunity. 2009

37. Long SA, Quan C, Van de Water J, et al. Immunoreactivity of organic mimeotopes of the E2 component of pyruvate dehydrogenase: connecting xenobiotics with primary biliary cirrhosis. $\mathrm{J}$ Immunol 2001;167:2956-2963. [PubMed: 11509645]

38. Selmi C, Gershwin ME. Bacteria and human autoimmunity: the case of primary biliary cirrhosis. Curr Opin Rheumatol 2004;16:406-410. [PubMed: 15201604]

39. Selmi C, Balkwill DL, Invernizzi P, et al. Patients with primary biliary cirrhosis react against a ubiquitous xenobiotic-metabolizing bacterium. Hepatology (Baltimore, Md 2003;38:1250-1257.

40. Mattner J, Savage PB, Leung P, et al. Liver autoimmunity triggered by microbial activation of natural killer T cells. Cell Host Microbe 2008;3:304-315. [PubMed: 18474357]

41. Selmi C, Ross SR, Ansari AA, et al. Lack of immunological or molecular evidence for a role of mouse mammary tumor retrovirus in primary biliary cirrhosis. Gastroenterology 2004;127:493-501. [PubMed: 15300582]

42. McDermid J, Chen M, Li Y, et al. Reverse transcriptase activity in patients with primary biliary cirrhosis and other autoimmune liver disorders. Aliment Pharmacol Ther 2007;26:587-595. [PubMed: 17661762]

43. Selmi C, Gershwin ME. The retroviral myth of primary biliary cirrhosis: is this (finally) the end of the story? Journal of hepatology. 2009 in press.

44. Tanaka A, Lindor K, Gish R, et al. Fetal microchimerism alone does not contribute to the induction of primary biliary cirrhosis. Hepatology (Baltimore, Md 1999;30:833-838. 
45. Invernizzi P, De Andreis C, Sirchia SM, et al. Blood fetal microchimerism in primary biliary cirrhosis. Clin Exp Immunol 2000;122:418-422. [PubMed: 11122249]

46. McCombe PA, Greer JM, Mackay IR. Sexual dimorphism in autoimmune disease. Current molecular medicine 2009;9:1058-1079. [PubMed: 19747114]

47. Alvaro D, Invernizzi P, Onori P, et al. Estrogen receptors in cholangiocytes and the progression of primary biliary cirrhosis. Journal of hepatology 2004;41:905-912. [PubMed: 15645536]

48. Larizza D, Calcaterra V, Martinetti M. Autoimmune stigmata in Turner syndrome: when lacks an X chromosome. Journal of autoimmunity 2009;33:25-30. [PubMed: 19349146]

49. Persani L, Rossetti R, Cacciatore C, et al. Primary Ovarian Insufficiency: X chromosome defects and autoimmunity. Journal of autoimmunity 2009;33:35-41. [PubMed: 19346101]

50. Pessach IM, Notarangelo LD. X-linked primary immunodeficiencies as a bridge to better understanding X-chromosome related autoimmunity. Journal of autoimmunity 2009;33:17-24. [PubMed: 19361956]

51. Carrel L, Willard HF. X-inactivation profile reveals extensive variability in X-linked gene expression in females. Nature 2005;434:400-404. [PubMed: 15772666]

52. Invernizzi P, Miozzo M, Selmi C, et al. X chromosome monosomy: a common mechanism for autoimmune diseases. J Immunol 2005;175:575-578. [PubMed: 15972694]

53. Invernizzi P, Miozzo M, Oertelt-Prigione S, et al. X monosomy in female systemic lupus erythematosus. Annals of the New York Academy of Sciences 2007;1110:84-91. [PubMed: 17911423]

54. Sawalha AH, Harley JB, Scofield RH. Autoimmunity and Klinefelter's syndrome: when men have two X chromosomes. Journal of autoimmunity 2009;33:31-34. [PubMed: 19464849]

55. Ozbalkan Z, Bagislar S, Kiraz S, et al. Skewed X chromosome inactivation in blood cells of women with scleroderma. Arthritis and rheumatism 2005;52:1564-1570. [PubMed: 15880831]

56. Brix TH, Knudsen GP, Kristiansen M, et al. High frequency of skewed X-chromosome inactivation in females with autoimmune thyroid disease: a possible explanation for the female predisposition to thyroid autoimmunity. The Journal of clinical endocrinology and metabolism 2005;90:5949-5953. [PubMed: 16105963]

57. Brix TH, Hansen PS, Bennedbak FN, et al. X Chromosome inactivation pattern is not associated with interindividual variations in thyroid volume: a study of euthyroid Danish female twins. Twin Res Hum Genet 2009;12:502-506. [PubMed: 19803777]

58. Chuang YH, Ridgway WM, Ueno Y, et al. Animal models of primary biliary cirrhosis. Clinics in liver disease 2008;12:333-347. ix. [PubMed: 18456184]

59. Wakabayashi K, Lian ZX, Moritoki Y, et al. IL-2 receptor alpha(-/-) mice and the development of primary biliary cirrhosis. Hepatology (Baltimore, Md 2006;44:1240-1249.

60. Oertelt S, Lian ZX, Cheng CM, et al. Anti-mitochondrial antibodies and primary biliary cirrhosis in TGF-beta receptor II dominant-negative mice. J Immunol 2006;177:1655-1660. [PubMed: 16849474]

61. Moritoki Y, Zhang W, Tsuneyama K, et al. B cells suppress the inflammatory response in a mouse model of primary biliary cirrhosis. Gastroenterology 2009;136:1037-1047. [PubMed: 19118554]

62. Irie J, Wu Y, Wicker LS, et al. NOD. c3c4 congenic mice develop autoimmune biliary disease that serologically and pathogenetically models human primary biliary cirrhosis. J Exp Med 2006;203:1209-1219. [PubMed: 16636131]

63. Amano K, Leung PS, Xu Q, et al. Xenobiotic-induced loss of tolerance in rabbits to the mitochondrial autoantigen of primary biliary cirrhosis is reversible. J Immunol 2004;172:6444-6452. [PubMed: 15128836]

64. Leung PS, Park O, Tsuneyama K, et al. Induction of primary biliary cirrhosis in guinea pigs following chemical xenobiotic immunization. J Immunol 2007;179:2651-2657. [PubMed: 17675529]

65. Wakabayashi K, Lian ZX, Leung PS, et al. Loss of tolerance in C57BL/6 mice to the autoantigen E2 subunit of pyruvate dehydrogenase by a xenobiotic with ensuing biliary ductular disease. Hepatology (Baltimore, Md 2008;48:531-540.

66. Lan RY, Salunga TL, Tsuneyama K, et al. Hepatic IL-17 responses in human and murine primary biliary cirrhosis. Journal of autoimmunity 2009;32:43-51. [PubMed: 19101114] 
67. Shimoda S, Nakamura M, Ishibashi H, et al. HLA DRB4 0101-restricted immunodominant T cell autoepitope of pyruvate dehydrogenase complex in primary biliary cirrhosis: evidence of molecular mimicry in human autoimmune diseases. J Exp Med 1995;181:1835-1845. [PubMed: 7536796]

68. Shimoda S, Harada K, Niiro H, et al. Biliary epithelial cells and primary biliary cirrhosis: the role of liver-infiltrating mononuclear cells. Hepatology (Baltimore, Md 2008;47:958-965.

69. Shimoda S, Ishikawa F, Kamihira T, et al. Autoreactive T-cell responses in primary biliary cirrhosis are proinflammatory whereas those of controls are regulatory. Gastroenterology 2006;131:606-618. [PubMed: 16890612]

70. Shimoda S, Nakamura M, Ishibashi H, et al. Molecular mimicry of mitochondrial and nuclear autoantigens in primary biliary cirrhosis. Gastroenterology 2003;124:1915-1925. [PubMed: 12806624]

71. Shimoda S, Nakamura M, Shigematsu H, et al. Mimicry peptides of human PDC-E2 163-176 peptide, the immunodominant T-cell epitope of primary biliary cirrhosis. Hepatology (Baltimore, Md 2000;31:1212-1216.

72. Kita H, Naidenko OV, Kronenberg M, et al. Quantitation and phenotypic analysis of natural killer T cells in primary biliary cirrhosis using a human CD1d tetramer. Gastroenterology 2002;123:10311043. [PubMed: 12360465]

73. Barak V, Selmi C, Schlesinger M, et al. Serum inflammatory cytokines, complement components, and soluble interleukin 2 receptor in primary biliary cirrhosis. Journal of autoimmunity 2009;33:178182. [PubMed: 19846277]

74. Shimoda S, Miyakawa H, Nakamura M, et al. CD4 T-cell autoreactivity to the mitochondrial autoantigen PDC-E2 in AMA-negative primary biliary cirrhosis. Journal of autoimmunity 2008;31:110-115. [PubMed: 18644699]

75. Yang GX, Lian ZX, Chuang YH, et al. Adoptive transfer of CD8(+) T cells from transforming growth factor beta receptor type II (dominant negative form) induces autoimmune cholangitis in mice. Hepatology (Baltimore, Md 2008;47:1974-1982.

76. Hsu W, Zhang W, Tsuneyama K, et al. Differential mechanisms in the pathogenesis of autoimmune cholangitis versus inflammatory bowel disease in interleukin-2Ralpha(-/-) mice. Hepatology (Baltimore, Md 2009;49:133-140.

77. Kita H, Matsumura S, He XS, et al. Quantitative and functional analysis of PDC-E2-specific autoreactive cytotoxic T lymphocytes in primary biliary cirrhosis. J Clin Invest 2002;109:1231-1240. [PubMed: 11994412]

78. Brusko TM, Putnam AL, Bluestone JA. Human regulatory T cells: role in autoimmune disease and therapeutic opportunities. Immunological reviews 2008;223:371-390. [PubMed: 18613848]

79. Jordan MA, Baxter AG. The genetics of immunoregulatory T cells. Journal of autoimmunity 2008;31:237-244. [PubMed: 18550334]

80. Aoki CA, Roifman CM, Lian ZX, et al. IL-2 receptor alpha deficiency and features of primary biliary cirrhosis. Journal of autoimmunity 2006;27:50-53. [PubMed: 16904870]

81. Zhang W, Sharma R, Ju ST, et al. Deficiency in regulatory T cells results in development of antimitochondrial antibodies and autoimmune cholangitis. Hepatology (Baltimore, Md 2009;49:545-552.

82. Lan RY, Cheng C, Lian ZX, et al. Liver-targeted and peripheral blood alterations of regulatory T cells in primary biliary cirrhosis. Hepatology (Baltimore, Md 2006;43:729-737.

83. Sasaki M, Ikeda H, Sawada S, et al. Naturally-occurring regulatory T cells are increased in inflamed portal tracts with cholangiopathy in primary biliary cirrhosis. Journal of clinical pathology 2007;60:1102-1107. [PubMed: 17158635]

84. Sakaki M, Hiroishi K, Baba T, et al. Intrahepatic status of regulatory T cells in autoimmune liver diseases and chronic viral hepatitis. Hepatol Res 2008;38:354-361. [PubMed: 18021223]

85. Selmi C, Zuin M, Gershwin ME. The unfinished business of primary biliary cirrhosis. Journal of hepatology 2008;49:451-460. [PubMed: 18640737]

86. Kikuchi K, Lian ZX, Yang GX, et al. Bacterial CpG induces hyper-IgM production in CD27(+) memory B cells in primary biliary cirrhosis. Gastroenterology 2005;128:304-312. [PubMed: 15685542] 
87. Moritoki Y, Lian ZX, Wulff $\mathrm{H}$, et al. AMA production in primary biliary cirrhosis is promoted by the TLR9 ligand CpG and suppressed by potassium channel blockers. Hepatology (Baltimore, Md 2007;45:314-322.

88. Mao TK, Lian ZX, Selmi C, et al. Altered monocyte responses to defined TLR ligands in patients with primary biliary cirrhosis. Hepatology (Baltimore, Md 2005;42:802-808.

89. Chuang YH, Lian ZX, Yang GX, et al. Natural killer T cells exacerbate liver injury in a transforming growth factor beta receptor II dominant-negative mouse model of primary biliary cirrhosis. Hepatology (Baltimore, Md 2008;47:571-580.

90. Zigmond E, Shalev Z, Pappo O, et al. NKT lymphocyte polarization determined by microenvironment signaling: a role for CD8+ lymphocytes and beta-glycosphingolipids. Journal of autoimmunity 2008;31:188-195. [PubMed: 18710796]

91. Lleo A, Invernizzi P, Gao B, et al. Definition of human autoimmunity - autoantibodies versus autoimmune disease. Autoimmunity reviews. 2009

92. Gershwin ME, Mackay IR, Sturgess A, et al. Identification and specificity of a cDNA encoding the $70 \mathrm{kd}$ mitochondrial antigen recognized in primary biliary cirrhosis. J Immunol 1987;138:35253531. [PubMed: 3571977]

93. Ishibashi H, Shimoda S, Gershwin ME. The immune response to mitochondrial autoantigens. Seminars in liver disease 2005;25:337-346. [PubMed: 16143949]

94. Oertelt S, Roman R, Selmi C, et al. A sensitive bead assay for antimitochondrial antibodies: chipping away at AMA negative PBC. Hepatology (Baltimore, Md. 2006 in press.

95. Invernizzi P, Crosignani A, Battezzati PM, et al. Comparison of the clinical features and clinical course of antimitochondrial antibody-positive and -negative primary biliary cirrhosis. Hepatology (Baltimore, Md 1997;25:1090-1095.

96. Muratori P, Muratori L, Ferrari R, et al. Characterization and clinical impact of antinuclear antibodies in primary biliary cirrhosis. Am J Gastroenterol 2003;98:431-437. [PubMed: 12591064]

97. Rigopoulou EI, Davies ET, Pares A, et al. Prevalence and clinical significance of isotype specific antinuclear antibodies in primary biliary cirrhosis. Gut 2005;54:528-532. [PubMed: 15753539]

98. Yang WH, Yu JH, Nakajima A, et al. Do antinuclear antibodies in primary biliary cirrhosis patients identify increased risk for liver failure? Clin Gastroenterol Hepatol 2004;2:1116-1122. [PubMed: 15625657]

99. Ardesjo B, Hansson CM, Bruder CE, et al. Autoantibodies to glutathione S-transferase theta 1 in patients with primary sclerosing cholangitis and other autoimmune diseases. Journal of autoimmunity 2008;30:273-282. [PubMed: 18242955]

100. Itoh S, Ichida T, Yoshida T, et al. Autoantibodies against a $210 \mathrm{kDa}$ glycoprotein of the nuclear pore complex as a prognostic marker in patients with primary biliary cirrhosis. J Gastroenterol Hepatol 1998;13:257-265. [PubMed: 9570238]

101. Miyachi K, Hankins RW, Matsushima H, et al. Profile and clinical significance of antinuclear envelope antibodies found in patients with primary biliary cirrhosis: a multicenter study. Journal of autoimmunity 2003;20:247-254. [PubMed: 12753810]

102. Invernizzi P, Wesierska-Gadek J, Battezzati PM, et al. Prognostic value of autoantibodies against proteins of nuclear pore complexes (anti-NPCs) in early primary biliary cirrhosis (PBC). Journal of hepatology 2004;40:159-160. [PubMed: 14672628]

103. Nakamura M, Shimizu-Yoshida Y, Takii Y, et al. Antibody titer to gp210-C terminal peptide as a clinical parameter for monitoring primary biliary cirrhosis. Journal of hepatology 2005;42:386392. [PubMed: 15710222]

104. Nakamura M, Kondo H, Mori T, et al. Anti-gp210 and anti-centromere antibodies are different risk factors for the progression of primary biliary cirrhosis. Hepatology (Baltimore, Md 2007;45:118127.

105. Ayres RC, Neuberger JM, Shaw J, et al. Intercellular adhesion molecule-1 and MHC antigens on human intrahepatic bile duct cells: effect of pro-inflammatory cytokines. Gut 1993;34:1245-1249. [PubMed: 8104850]

106. Saidman SL, Duquesnoy RJ, Zeevi A, et al. Recognition of major histocompatibility complex antigens on cultured human biliary epithelial cells by alloreactive lymphocytes. Hepatology (Baltimore, Md 1991;13:239-246. 
107. Tanaka A, Nalbandian G, Leung PS, et al. Mucosal immunity and primary biliary cirrhosis: presence of antimitochondrial antibodies in urine. Hepatology (Baltimore, Md 2000;32:910-915.

108. Reynoso-Paz S, Leung PS, Van De Water J, et al. Evidence for a locally driven mucosal response and the presence of mitochondrial antigens in saliva in primary biliary cirrhosis. Hepatology (Baltimore, Md 2000;31:24-29.

109. Matsumura S, Van De Water J, Leung P, et al. Caspase induction by IgA antimitochondrial antibody: IgA-mediated biliary injury in primary biliary cirrhosis. Hepatology (Baltimore, Md 2004;39:14151422.

110. Lleo A, Selmi C, Invernizzi P, et al. The consequences of apoptosis in autoimmunity. Journal of autoimmunity 2008;31:257-262. [PubMed: 18513925]

111. Odin JA, Huebert RC, Casciola-Rosen L, et al. Bcl-2-dependent oxidation of pyruvate dehydrogenase-E2, a primary biliary cirrhosis autoantigen, during apoptosis. J Clin Invest 2001;108:223-232. [PubMed: 11457875]

112. Allina J, Stanca CM, Garber J, et al. Anti-CD16 autoantibodies and delayed phagocytosis of apoptotic cells in primary biliary cirrhosis. Journal of autoimmunity 2008;30:238-245. [PubMed: 18023559]

113. Padgett KA, Lan RY, Leung PC, et al. Primary biliary cirrhosis is associated with altered hepatic microRNA expression. Journal of autoimmunity 2009;32:246-253. [PubMed: 19345069]

114. Sasaki M, Ikeda H, Nakanuma Y. Activation of ATM signaling pathway is involved in oxidative stress-induced expression of mito-inhibitory p21WAF1/Cip1 in chronic non-suppurative destructive cholangitis in primary biliary cirrhosis: an immunohistochemical study. Journal of autoimmunity 2008;31:73-78. [PubMed: 18456456]

115. Shoenfeld Y, Selmi C, Zimlichman E, et al. The autoimmunologist: geoepidemiology, a new center of gravity, and prime time for autoimmunity. Journal of autoimmunity 2008;31:325-330. [PubMed: 18838248]

116. Salas JT, Banales JM, Sarvide S, et al. Ae2a,b-deficient mice develop antimitochondrial antibodies and other features resembling primary biliary cirrhosis. Gastroenterology 2008;134:1482-1493. [PubMed: 18471521] 


\section{Table 1}

Similarities of the acquired and innate immunity compartments between the murine models and human PBC.

\begin{tabular}{|c|c|c|c|}
\hline Model & Adaptive immunity & Innate immunity & Ref. \\
\hline Ae2(a.b)-deficient & $\begin{array}{l}\text { - AMA } \\
\text { - Lymphocytic CD8+ infiltrates } \\
\text { - Decreased T regulatory cells } \\
\text { - PBC-like liver lesions }\end{array}$ & -- & (116) \\
\hline $\begin{array}{l}\text { Xenobiotic on } \\
\text { C57BL/6 }\end{array}$ & $\begin{array}{l}\text { - AMA } \\
\text { - Lymphocytic CD8+ infiltrate } \\
\text { - PBC-like liver lesions }\end{array}$ & -- & (65) \\
\hline NOD.c3c4 & $\begin{array}{l}\text { - AMA, ANA } \\
\text { - lymphocytic infiltrate }\end{array}$ & -- & (62) \\
\hline IL2Ra $^{-/-}$ & $\begin{array}{l}\text { - AMA } \\
\text { - portal tract CD4+ and CD8+ cells }\end{array}$ & -- & (59) \\
\hline dnTGFbRII & $\begin{array}{l}\text { - AMA } \\
\text { - Deficient T reg function }\end{array}$ & NKT cells worsen liver injury & (60) \\
\hline $\begin{array}{l}\text { N. aromaticivorans on } \\
\text { NOD } 1101\end{array}$ & $\begin{array}{l}\text { - AMA } \\
\text { - PBC-like liver lesions } \\
\text { - Disease transfer by T cells }\end{array}$ & NKT cells are required & (40) \\
\hline
\end{tabular}




\section{Table 2}

Major autoantigens in PBC.

\begin{tabular}{|c|c|}
\hline \multicolumn{2}{|l|}{ Mitochondrial proteins } \\
\hline E2 subunits of 2-OADC & PDC-E2 * \\
\hline & OGDC-E2 * \\
\hline & BCOADC-E2 * \\
\hline \multirow[t]{2}{*}{ Pyruvate dehydrogenase complex } & E3BP * \\
\hline & PDC E1 $\alpha$ \\
\hline \multicolumn{2}{|l|}{ Nuclear proteins } \\
\hline \multirow[t]{2}{*}{ Multiple nuclear dots } & Sp100 \\
\hline & PML \\
\hline \multirow[t]{2}{*}{ Nuclear pore complex } & gp210* \\
\hline & nucleoporin p62* \\
\hline Centromeres & CENP A, B and C \\
\hline
\end{tabular}

Abbreviations: 2-OADC: 2-oxo-acid dehydrogenase complex; PDC: pyruvate dehydrogenase complex; OGDC: oxoglutarate dehydrogenase complex; BCOADC: branched chain 2-oxo-acid dehydrogenase complex; E3BP: dihydrolipoamide dehydrogenase (E3) - binding protein 
Table 3

Imunopathologic characteristics of cholangiocytes in PBC.

\begin{tabular}{|c|c|c|}
\hline & PBC & Normal \\
\hline $\begin{array}{l}\text { PDC-E2 expression } \\
\text { Adhesion molecules } \\
\text { - ICAM-1 } \\
\text { - VCAM-1 } \\
\text { - LFA-1 } \\
\text { - E-selectins } \\
\text { Biliary intra-epithelial lymphocytes } \\
\text { Cytokines } \\
\text { - INF- } \gamma \\
\text { - IL-2 } \\
\text { - IL-6 } \\
\text { - IL-6 receptor } \\
\text { - TNF- } \alpha \\
\text { - TNF receptor }\end{array}$ & $\begin{array}{c}++ \\
++ \\
+ \\
+ \\
++ \\
\text { Small bile ducts, increased CD4 }{ }^{+} \mathrm{CD} 28^{-} \\
++ \\
++ \\
++ \\
-/+ \\
++ \\
++\end{array}$ & $\begin{array}{c}+ \\
-/+ \\
-/+ \\
\text { Large bile ducts, few CD4 } \\
- \\
- \\
- \\
- \\
-/+ \\
-/+\end{array}$ \\
\hline $\begin{array}{l}\text { BEC phagocytosis of apoptotic } \\
\text { BECs } \\
\text { Apoptosis-related molecules } \\
\text { - Fas (CD95) } \\
\text { - granzyme B } \\
\text { - perforin } \\
\text { - bcl-2 }\end{array}$ & $\begin{array}{c} \\
+ \\
-/+ \\
-/+ \\
-\end{array}$ & $\begin{array}{l}- \\
- \\
- \\
++\end{array}$ \\
\hline
\end{tabular}

